\title{
Tolerance to solid organ transplants through transfer of MHC class II genes
}

\author{
Kai-C. Sonntag, ${ }^{1}$ David W. Emery, ${ }^{2}$ Akihiko Yasumoto, ${ }^{3}$ Gary Haller, ${ }^{4}$ Sharon Germana, ${ }^{1}$ \\ Tomasz Sablinski, ${ }^{5}$ Akira Shimizu, ${ }^{6}$ Kazuhiko Yamada, ${ }^{1}$ Hideaki Shimada, ${ }^{3}$ Scott Arn, ${ }^{1}$ \\ David H. Sachs, ${ }^{1}$ and Christian LeGuern ${ }^{1}$
}

\author{
${ }^{1}$ Transplantation Biology Research Center, Massachusetts General Hospital/Harvard Medical School, Boston, \\ Massachusetts, USA \\ ${ }^{2}$ Division of Medical Genetics, University of Washington, Seattle, Washington, USA \\ ${ }^{3}$ Department of Surgery (II), Chiba University School of Medicine, Chiba, Japan \\ ${ }^{4}$ Klinikum Mannheim GmbH, Chirurgische Klinik, Mannheim, Germany \\ ${ }^{5}$ Novartis Pharmaceuticals, Clinical Research and Development, East Hanover, New Jersey, USA \\ ${ }^{6}$ Department of Pathology, Nippon Medical School, Tokyo, Japan \\ Address correspondence to: Christian LeGuern, Transplantation Biology Research Center, Massachusetts General Hospital, \\ MGH-East, Building 149-9019, 13th Street, Boston, Massachusetts 02129, USA. \\ Phone: (617) 726-4059; Fax: (617) 726-4067; E-mail: leguern@helix.mgh.harvard.edu.
}

Received for publication August 10, 2000, and accepted in revised form November 21, 2000.

\begin{abstract}
Donor/recipient MHC class II matching permits survival of experimental allografts without permanent immunosuppression, but is not clinically applicable due to the extensive polymorphism of this locus. As an alternative, we have tested a gene therapy approach in a preclinical animal model to determine whether expression of allogeneic class II transgenes ( $\mathrm{Tg}$ 's) in recipient bone marrow cells would allow survival of subsequent Tg-matched renal allografts. Somatic matching between donor kidney class II and the recipient Tg's, in combination with a short treatment of cyclosporine A, prolonged graft survival with DR and promoted tolerance with DQ. Class II Tg expression in the lymphoid lineage and the graft itself were sequentially implicated in this tolerance induction. These results demonstrate the potential of MHC class II gene transfer to permit tolerance to solid organ allografts.
\end{abstract}

J. Clin. Invest. 107:65-71 (2001).

\section{Introduction}

The use of potent immunosuppressive drugs in clinical transplantation has extended the survival of vascularized allografts despite genetic disparities at the MHC class I and class II loci (1). Drug-induced nonspecific immunosuppression is, however, associated with clinical complications (2) that potentially could be avoided by inducing graft-specific tolerance. Permanent graftspecific unresponsiveness has previously been demonstrated in miniature swine treated with cyclosporine $\mathrm{A}$ (CsA) for only 12 days, provided that the donor and recipient shared identity at the class II locus (3).

The beneficial impact of class II matching on the outcome of renal allografts has also been documented in clinical transplantation (4). Since matching exclusively for class II would be difficult to achieve in clinical settings, we tested the principle of creating a somatic match by introducing class II genes into hematopoietic cells of prospective allograft recipients. A pilot study in one animal has recently confirmed the technical feasibility of this approach and documented that expression of an allogeneic pig class II DRB cDNA in bone marrow-derived (BMderived) cells could modulate $\mathrm{T}$-cell reactivity to donor antigens (5). In this report, we present evidence for induction of operational transplantation tolerance to fully allogeneic renal allografts following the introduction of a graft-matched DR or DQ allele into the recipient's immune cells.

\section{Methods}

Animals and protocols used in this study. Massachusetts General Hospital Miniature Swine (3-5 months old) received either allogeneic or syngeneic MHC class II cDNA through transduction of autologous bone marrow cells (BMCs) (Table 1). The development of the GS4.5 and GS7.3 recombinant retrovirus vectors containing the swine DRB cDNA of the $d$ and $c$ alleles, respectively, as well as the development of the construct NAB.V expressing the DQA and DQB cDNA from the $c$ haplotype have been described (5-7). Derivation of high titer retrovirus producer clones, conditions of virus producer cells, collection of viruscontaining supernatants, and transduction of whole BMCs were as described (8). Cytokines were used as follows: murine kit ligand and human IL-3/GM-CSF fusion molecule PIXY321, both provided by Immunex Corp. (Seattle, Washington, USA), or recombinant porcine cytokines IL-3, GM-CSF, and stem cell factor (SCF), kindly provided by BioTransplant Inc. (Boston, Massachusetts, USA). Recipients were conditioned with 5 Gy whole body irradiation given at days -1 and 
Table 1

Animals used in this study

\begin{tabular}{|c|c|c|c|c|c|}
\hline $\begin{array}{c}\text { Animal no. } \\
\text { (SLA haplotype) }\end{array}$ & $\begin{array}{c}\text { Transduction } \\
\text { (Gene } \rightarrow \text { haplotype) }\end{array}$ & $\begin{array}{l}\text { KTx donor } \\
\text { (Haplotype) }\end{array}$ & $\begin{array}{c}\mathrm{KTx} \\
\text { (days after BMT) }\end{array}$ & $\begin{array}{l}\text { Outcome of first } \\
\text { kidney graft }\end{array}$ & $\begin{array}{l}\text { Outcome of secon } \\
\text { kidney graft }\end{array}$ \\
\hline \multicolumn{6}{|c|}{ Allogeneic gene transfer } \\
\hline $\begin{array}{l}10736(\mathrm{cc}) \\
11585(\mathrm{gg}) \\
11782(\mathrm{cc}) \\
12307(\mathrm{dd}) \\
12426(\mathrm{dd})\end{array}$ & $\begin{array}{c}\left\|\left.^{d}(D R B) \rightarrow\right|^{c} /\right\|^{c} \\
\left\|\left.^{c}(D R B) \rightarrow\right|^{c} /\right\|^{d} \\
\left\|\left.^{d}(D R B) \rightarrow\right|^{c} /\right\|^{c} \\
\left\|I^{c}(D Q A+B) \rightarrow l^{d} /\right\|^{d} \\
\left\|c(D Q A+B) \rightarrow l^{d} /\right\|^{d}\end{array}$ & $\begin{array}{l}\mathrm{dd}\left(I^{d} / I^{d}\right) \\
\mathrm{jj}\left(I^{\mathrm{a} /} /\left.\right|^{c}\right) \\
\mathrm{dd}\left(I^{d} / I^{d}\right) \\
\operatorname{cc}\left(I^{c} / I^{c}\right) \\
\operatorname{cc}\left(I^{c} / I^{c}\right)\end{array}$ & $\begin{array}{l}150 \\
150 \\
273 \\
150 \\
150\end{array}$ & $\begin{array}{c}\text { sacrifice day } 1120 \\
\text { graft-loss day } 322 \\
\text { graft-loss day } 184 \\
\text { sacrifice day } 500 \\
\text { tolerant day } 658\end{array}$ & $\begin{array}{l}\text { graft-loss day } 29 \\
\text { graft-loss day } 108 \\
\text { tolerant day } 139\end{array}$ \\
\hline \multicolumn{6}{|c|}{ Syngeneic gene transfer } \\
\hline $\begin{array}{l}10807(\mathrm{cc}) \\
11077(\mathrm{cc}) \\
11625(\mathrm{cc}) \\
13286(\mathrm{cc})\end{array}$ & $\begin{array}{c}\|\left.^{c}(\text { DRB }) \rightarrow\right|^{c} / \|^{c} \\
\left\|\left.^{c}(D R B) \rightarrow\right|^{c} /\right\|^{c} \\
\left\|\left.^{c}(D R B) \rightarrow\right|^{c} /\right\|^{c} \\
\left\|\left.^{c}(D Q A+B) \rightarrow\right|^{c} /\right\|^{c}\end{array}$ & $\begin{array}{l}\text { dd }\left(I^{d} / I^{d}\right) \\
\text { dd }\left(I^{d} / I^{d}\right) \\
d d\left(I^{d} / I^{d}\right) \\
d d\left(I^{d} / I^{d}\right)\end{array}$ & $\begin{array}{l}150 \\
150 \\
150 \\
150\end{array}$ & $\begin{array}{l}\text { rejection day } 120 \\
\text { rejection day } 5 \\
\text { rejection day } 82 \\
\text { rejection day } 39\end{array}$ & \\
\hline
\end{tabular}

Animals as well as BMC transductions, BMT, and KTx are described in Methods. The SLA haplotypes and alleles at the class I (I) and class II (II) loci are indicated.

0 (10 Gy total) prior to reinfusion of transduced BMCs $\left(0.4-1.3 \times 10^{8}\right.$ cells $\left./ \mathrm{kg}\right)$. Allogeneic kidney transplantation (KTx) was performed either 150 or 273 days after bone marrow transplantation (BMT) with CsA treatment $(10 \mathrm{mg} / \mathrm{kg}$ per day) for 12 days, starting on the day of transplantation (9).

Detection of BM transduction rates by G418-resistant GMCFUs. G418-resistant GM-CFUs (G418r GM-CFUs) were evaluated as previously described (8), and the net percent of transduced G418 ${ }^{\mathrm{r}} \mathrm{GM}-\mathrm{CFU}$ s was calculated by subtracting untransduced control G418 ${ }^{\mathrm{r}}$ GM-CFUs from transduced G418 ${ }^{\mathrm{r}}$ GM-CFUs at cytotoxic concentrations of G418.

Detection of transgene $m R N A$ by RT-PCR. DNA and RNA preparations from whole blood cell (WBC) and BM samples were done as previously described (5). For cDNA preparation, 3-5 $\mathrm{g}$ of sample RNA was first DNase-digested (Deoxyribonuclease I, Amplification Grade; Life Technologies Inc., Gaithersburg, Maryland, USA) under conditions recommended by the manufacturer, and then transcribed into cDNA using the SuperScript Preamplification Kit (Life Technologies Inc.). DNA and cDNA were analyzed by a nested PCR technique using oligonucleotide primers specific for vector $\mathrm{DRB}, \mathrm{DQB}$, and long terminal repeat (LTR) sequences as follows: DRB-1 (5'-CTCAGAGTGGAGAGGTCTACAG-3'), and DQB-1 (5'-AGATAGAGGAAGGCACGACC- $\left.3^{\prime}\right)$ with LTR-1 (5'-TACCACAGATATCCTGT TTGGCC $\left.-3^{\prime}\right)$ in the first PCR reaction, and the primers DRB-2 (5'-GTCACAGTGG AATGGAGGGCAC-3'), and DQB-2 (5'-TTAGGAACGGAGACTGGACC-3') with LTR2 (5'-GTTCCATCTGTTCCTGACCTTG-3') in the second PCR reaction. Conditions for PCR reactions were: First PCR: in a total reaction volume of $50 \mu \mathrm{l} ; 0.5-1 \mu \mathrm{g}$ DNA or $2-15 \mu \mathrm{l}$ of the cDNA reaction, $1.4 \mathrm{nM}$ of each primer, $100 \mathrm{mM}$ dioxynucleotide triphosphates (dNTP), 1X Assay Buffer A (Fisher Scientific, Pittsburgh, Pennsylvania, USA), 2.5 units of Taq I DNA polymerase (Fisher Scientific); amplification in a PTC100 MJ Thermocycler (MJ-Research Inc., Waltham, Massachusetts, USA): denaturing step at $94^{\circ} \mathrm{C}$ for 1 minute, annealing step at $55^{\circ} \mathrm{C}$ for 30 seconds, and amplification step at $72^{\circ} \mathrm{C}$ for 45 seconds, for 35 cycles. Second PCR: in a total reaction volume of $50 \mu \mathrm{l}$; $2.5 \mu \mathrm{l}$ of the first PCR reaction, $1.4 \mathrm{nM}$ of each primer, 100 mM dNTP, 1x Opti-Prime buffer no. 6 (Stratagene, La Jolla, California, USA), 2.5 units of Taq I DNA polymerase (Fisher Scientific); amplification as described above (30 cycles). The exon $3^{\prime}$-specific actin primers 5'-AACCCCAAGGCCAACCGCGAGAAGATGACC$3^{\prime}$ and $5^{\prime}$-GgTGATGACCTGGCCGTCAGGCAGCTCGTA$3^{\prime}$ were used in the PCR experiments to test the quality of the cDNA template. PCR products were analyzed on 3\% NuSieve GTG electrophoresis gels (BioWhittaker Molecular Applications, Rockland, Maine, USA) stained with ethidium bromide.

Detection of transgene expression in different hematopoietic cell lineages. T-cell and macrophage purification procedures included either flow cytometry (FCM) cell sorting (FACScan II; BD Immunocytometry Systems, San Jose, California, USA) or positive magnetic bead selection using the MACS system (Miltenyi Biotec, Auburn, California, USA). T and natural killer (NK) cells were sorted by using the anti-pig CD2 (MSA4) (10) and monocytes/granulocytes $(\mathrm{M} / \mathrm{G})$ by an anti-pig $\mathrm{M} / \mathrm{G}$ (74-22-15A) (11) murine mAb. FCM-sorted cells were stained at saturating $\mathrm{Ab}$ concentrations for 30 minutes at $4^{\circ} \mathrm{C}$. MACS cell purification involved cell incubation with $\mathrm{Ab}$ for 15 minutes at $4^{\circ} \mathrm{C}$ followed by interaction with rat anti-mouse IgG1 or IgG2a mAb coupled to superparamagnetic MACS microbeads. Cell-bead complexes were then passed through a separation column (BS) placed in a magnetic separator. Cells collected as the magnetic fraction were analyzed in FCM assays to evaluate the T-cell as well as monocyte phenotype and respective contamination with other cell types. Purity of cell fractions ranged from 97 to $99 \%$.

Histopathology of kidney biopsies. Sequential wedge kidney biopsies were performed on postoperative days (PODs) 30, 60, 100, and >100 through a flank incision. Tissues were stained using hematoxylin and eosin, and coded slides were examined according to standard 
pathologic criteria (12) based on the "Banff Schema" of the International Society of Nephrology as applied to clinical KTx (13). All animals that died underwent complete postmortem examinations.

Mixed lymphocyte reaction assays. Mixed lymphocyte reaction (MLR) culture conditions for porcine T-cell proliferation have been described previously (14). Briefly, $4 \times 10^{5}$ peripheral blood lymphocyte $(\mathrm{PBL})$ responders from experimental (Table 1) or naive control (swine leukocyte antigen [SLA] $d$ haplotype) animals were mixed with an equal number of irradiated (25 Gy) stimulator PBLs (SLA $c$ haplotype and Yucatan pig [YUC] as third-party control) and were incubated in $200 \mu \mathrm{l}$ of standard MLR media using flat-bottomed 96-well plates (Costar, Cambridge, Massachusetts, USA). After 5 days of incubation, $1 \mu \mathrm{Ci}$ of ${ }^{3} \mathrm{H}$-thymidine was added to each well, followed by an additional 5 -hour incubation. ${ }^{3} \mathrm{H}$ incorporation into newly synthesized polynucleotides was determined in triplicate samples by liquid scintillation. Stimulation indices (SI) were derived by dividing cpm of individual alloresponses with the corresponding cpm of self-response. The percentages of anti-donor versus third party response were calculated as follows: SI experimental / SI third party YUC $\times 100$. Responses against thirdparty YUC ranged between 7,500 and 241,000 cpm.

Statistical analyses. Group comparisons were made by Student's $t$ test. Values of BM transduction rates were evaluated by G418 ${ }^{\mathrm{r}} \mathrm{GM}-\mathrm{CFU}$ s as previously described (8). Graft survival data were based on blood creatinine levels and histopathology of rejected grafts. $P$ values less than 0.05 were considered statistically significant.

\section{Results}

Gene transfer of MHC class II in BMCs of recipients. As in humans, the pig DR $\alpha$ polypeptide sequence is invariant, whereas the DR $\beta, D Q \alpha$, and DQ $\beta$ sequences are polymorphic (15). To ensure the transfer of a fully allogeneic class II, retroviral vectors were constructed to express either the DR $\beta$ (DRB cDNA) chain along with the gene for neomycin resistance $\left(\mathrm{Neo}^{\mathrm{r}}\right)(6,8)$ or the $\mathrm{DQ} \alpha$ and $\beta$ (DQA+B) chains (7). Animals included in this study received either allogeneic or control syngeneic DRB or DQA+B cDNA through transduction of autologous BMCs (Table 1) $(5,8)$. Levels of $\mathrm{DRB}$ vector expression were evaluated by the percentage of G418 ${ }^{\mathrm{r}} \mathrm{GM}-\mathrm{CFUs}$ in serial rib biopsies (8). We have previously shown that initial BMC transduction rates of $8.9 \pm 2.1 \%$ were not sufficient to permit the induction of specific tolerance to transgene-matched (Tg-matched) renal allografts (5). The addition of murine c-kit ligand and human IL-3/GM-CSF fusion molecule PIXY321 (8) or the recombinant porcine cytokines IL-3, GM-CSF, and SCF substantially increased the initial transduction levels to $21.3 \pm 3.5 \%$ G418 ${ }^{\mathrm{r}}$ GM-CFUs $(P<0.02$ as compared with transduction without cytokines). Drug-resistant GM-CFUs were still detected in BMCs of all transplanted recipients at the time of immunological reconstitution at approximately 120 days after BMT, as well as at the time of KTx (data not shown). The percentage of G418 ${ }^{\mathrm{r}}$ GM-CFUs declined uniformly in all animals, a decay that may correlate with the turnover rate of transduced cells. Due to the absence of a selectable marker in the DQ vector, transduction rates were estimated by PCR analysis of randomly picked unselected GM-CFUs. DQ proviral sequences were detected in approximately $10 \%$ of single colonies, suggesting lower transduction rates as compared with those observed with the DR gene transfer (data not shown).

Long-term expression of the class II Tg. DRB and DQB Tg presence and transcription in vivo was monitored in $\mathrm{BM}$ and WBC samples by a nested PCR designed to amplify proviral DNA and cDNA, respectively. Using these assays, transgenic DRB mRNA was detected up to 413 days after BMT in samples from long-term graft-accepting animals (Figure 1). Transcription of the DRB Tg was confirmed at time of KTx as shown previously (5), but ceased around 171 days before graft loss (no. 11585, Figure 1b). In contrast, DQ Tg presence and expression were detected only up to 84 days after BMT for animal no. 12307 and were, consequently, no longer present at time of KTx (Figure 1b, arrows).

$D R B T g$ expression in hematopoietic lineages. Lineage distribution of DRB Tg expression was evaluated by RT-PCR of RNA isolated from antibody-sorted CD2 ${ }^{+}$ cells or $M / G$ subpopulations from peripheral blood (Table 2). Transcription of the Tg was observed at various time points in the $\mathrm{M} / \mathrm{G}$ lineage of the five animals studied, including those recipients whose BMCs were transduced in the absence of cytokines with resultant lower transduction efficiencies (5). In contrast, the long-term graft-accepting animals, which received BMCs transduced in the presence of cytokines, exhibited additional $\mathrm{Tg}$ expression in the $\mathrm{CD} 2^{+}$lymphoid/NK lineage (Table 2). The short expression course of Tg in DQ-engineered pigs (Figure 1) did not allow similar lineage analyses.

Graft survival in genetically engineered pigs. The impact of DR or DQ Tg matching on the immunity of the class II-engineered animals was evaluated by chal-

\section{Table 2}

Detection of Tg expression in different hematopoietic cell lineage by RT-PCR

\begin{tabular}{|c|c|c|c|c|}
\hline \multirow{2}{*}{$\begin{array}{l}\text { Animal } \\
\text { no. }\end{array}$} & \multirow[b]{2}{*}{ Cytokines } & \multicolumn{2}{|c|}{$\begin{array}{l}\text { Last day positive } \\
\text { for Tg RT-PCR }\end{array}$} & \multirow{2}{*}{$\begin{array}{c}\text { Graft survival } \\
\text { (days) }\end{array}$} \\
\hline & & Myeloid & Lymphoid & \\
\hline 10736 & + & 364 & 364 & 1120 \\
\hline 11782 & + & 385 & 385 & 184 \\
\hline $10660^{\mathrm{A}}$ & - & 154 & $\varnothing$ & 10 \\
\hline $10680^{A}$ & - & 154 & $\varnothing$ & 22 \\
\hline $10697^{A}$ & - & 154 & $\varnothing$ & 40 \\
\hline
\end{tabular}

Purification of T-cell and M/G fractions, as well as detection of Tg transcription, was as described in Methods. + and - indicate the presence or absence of cytokines during BMC transduction, respectively. $\varnothing$, no detection of Tg transcripts. ${ }^{A}$ Animals no. 10660, 10680, and 10697 received autologous BMC transduced with an allogeneic MHC class II DRB CDNA in the absence of cytokines as described (5). 
a
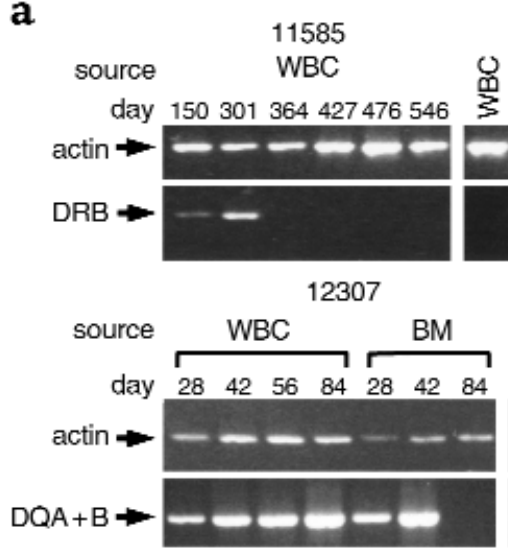
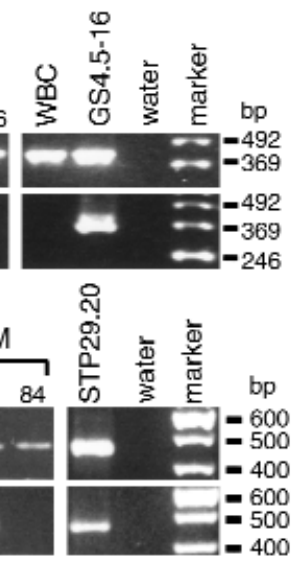

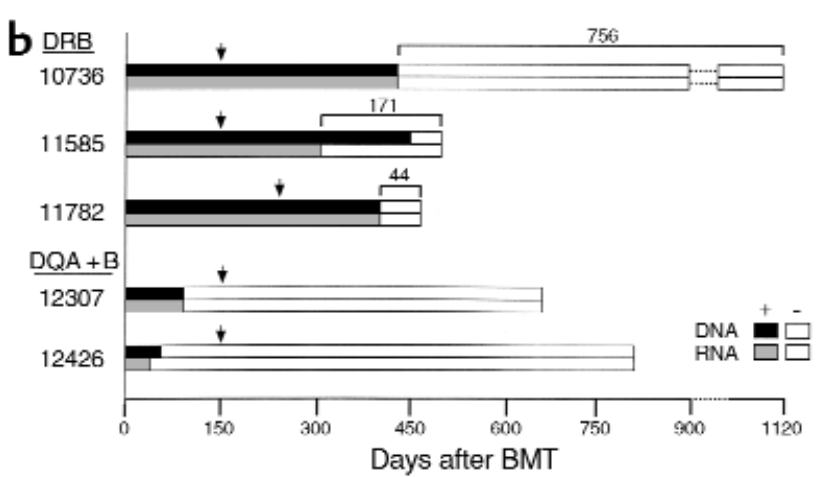

Days after BMT

Figure 1

PCR analysis of MHC class II DRB and DQB transgenes. (a) Results from a representative long-term graft-accepting animal, no. 11585 (DRB, top), and a tolerant animal, no. 12307 (DQA+B, bottom). WBC and BM samples, taken at various time points after BMT, were analyzed for actin and retroviral DRB or DQB cDNA. Specific PCR products for actin (414 bp), DRB (358 bp), and DQB (461 bp) are shown. GS4.5-16 and STP29.20 are DRB- and DQA+B-virus producing cell clones, respectively. (b) RT-PCR and DNA-PCR analyses performed on WBC and BM samples from long-term graft-accepting pigs. Filled, gray, and open bars indicate the presence of DRB or DQB Tg DNA, DRB or DQB Tg transcription, and graft survival, respectively. KTx was performed at times indicated by arrows. Numbers over brackets show graft persistence (in days) following cessation of Tg transcription.

lenging the BM-reconstituted recipients with kidney grafts that were class II identical to the Tg but fully disparate to the recipient MHC. All pigs received a graft either at 150 or 273 days after BMT along with a 12 day course of CsA to prevent T-cell reactivity to the class I disparity (3) (Table 1). As shown in Figure 2c, control animals engineered to express the syngeneic class II Tg rejected their transplants between 5 and 120 days (mean survival time $=60 \pm 50.1$ days), a time frame similar to that reported for the survival of fully mismatched kidneys under the same immunosuppressive regimen (3). These animals never exhibited normal renal function and eventually lost their grafts as a consequence of acute cellular rejection (ACR) (Figure $3 \mathrm{~b}$ ). Recipient animals engineered with the allogeneic class II DR demonstrated either full acceptance (no. 10736) or significantly prolonged survival $(P=0.0246)$ of DR Tg-identical grafts, with stable renal function for at least 170 days (Figure 2a). Two of the latter animals, nos. 11782 and 11585 , eventually lost their grafts at PODs 184 and 322, respectively, due to a chronic allograft glomerulopathy (CAG) and/or chronic rejection (Figure 3a). In contrast to the DR-treated recipients, the animals that received the allogeneic class II DQA ${ }^{+} B$ genes developed full unresponsiveness to the DQ Tg-identical transplants, without exhibiting clinical or histopathological signs of graft rejection (Figures $2 \mathrm{~b}$ and $3 \mathrm{c}$ ).

Possible mechanisms involved in tolerance induction. In an attempt to understand the mechanisms which may control hyporesponsiveness to kidney allografts, a second set of kidney transplants, MHC-matched to the first grafts, were implanted into two of the DR- and one of the DQ-engineered animals without further CsA treatment. The two nontolerant DR animals, nos. 11585 and 11782 , accepted the second graft for 29 and 108 days, respectively, although blood creatinine never reached basal levels (Figure 2a). Loss of the grafts was attributed to ACR for no. 11585 and to CAG for no. 11782. Survival of the second grafts in these animals was markedly increased compared with the 7-day survival of a first graft implanted in a Tg-engineered pig without CsA treatment (data not shown). The tolerant DQ animal, however, which was

\section{Figure 2}

Outcome of allogeneic kidney grafts in the genetically engineered animals. Blood creatinine levels $(\mathrm{mg} / \mathrm{dl})$ of allogeneic DRB-engineered (a) and DQA+B-engineered animals (b) are displayed. Inset (c) shows results from syngeneic DRB-engineered and DQA+B-engineered control animals. Arrows indicate time of second transplantation of Tg-matched kidney grafts without CsA treatment.

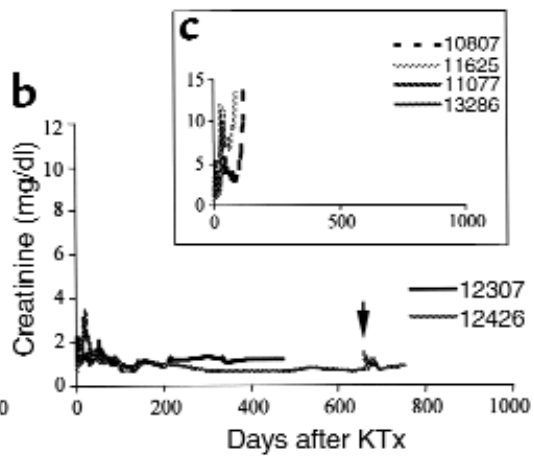


already unresponsive to the first graft, accepted the second SLA-matched kidney for the entire period of the study without immunosuppression (139 days, Figure $2 \mathrm{~b}$ ). The second transplant displayed normal renal function as well as no histological indication of cellular or humoral rejection. Since the BMT and the short-term immunosuppressive treatment may have had cumulative effects upon the induction of nonspecific hyporesponsiveness, the immune status of this DQ recipient was tested with a third-party allograft. When the second transplant was replaced with an outbred pig allograft at POD 139, rejection occurred within 5 days, demonstrating the specificity of tolerance as well as the immune competence of the recipient (data not shown).

To further investigate the role of the graft in this specific unresponsiveness, peripheral T-cell activation was examined in three DQ-engineered (including one rejector animal) and three DR-engineered animals by MLR assays. Results in Figure 4 indicated that, prior to kidney grafting, all pigs tested had full in vitro peripheral T-cell immunocompetence to the subsequently grafted tissues. A progressive decrease of antidonor reactivity was, however, observed following KTx in the two tolerant DQ animals. A comparable decrease in anti-donor $\mathrm{T}$-cell proliferation was detected in three DR-transferred animals 100 days after KTx (Figure 4). These findings were indicative of a concomitant role of the class II Tg and the graft itself in induction of tolerance. In addition, persistence of allografts in the engineered animals coincided with the disappearance of peripheral T-cell cytotoxicity to donor-specific antigens (results not shown).

\section{Discussion}

The present study demonstrates, for the first time to our knowledge, the potential of somatic transgenesis of MHC class II genes for the induction of transplantation tolerance to vascularized organs. We have shown that the transfer and expression of a single allogeneic MHC class II molecule in BMCs of reconstituted animals allows prolonged survival of subsequent $\mathrm{Tg}$ matched kidney allografts without permanent pharmacological immunosuppression. The aftermath of somatic class II matching on graft survival is dependent upon the nature of the class II genes transferred as well as the timing of their expression. While early expression of the allogeneic DR prolonged kidney graft survival, DQ promoted the induction of tolerance.

Although transcription of proviral DR mRNA could reach substantial levels as detected in WBC by Northern blotting up to 28 weeks after BMT (5), we believe that overall the quantity of retroviral material transcribed in peripheral cells was very low, since RT-PCR was required for its detection (Figure 1). Alternatively, a limited number of peripheral clones with higher levels of $\mathrm{Tg}$ expression may have been present but were not detected by our method of analysis. The results from the lineage studies in the DR-engineered recipi- ents (Table 2) supported this view by showing that $\mathrm{Tg}$ expression in the lymphoid lineage coincided with graft survival. This correlation also suggests that the use of cytokines during BM transduction resulted in the transduction of a subpopulation of toleranceinducing cells of lymphoid origin, possibly thymic
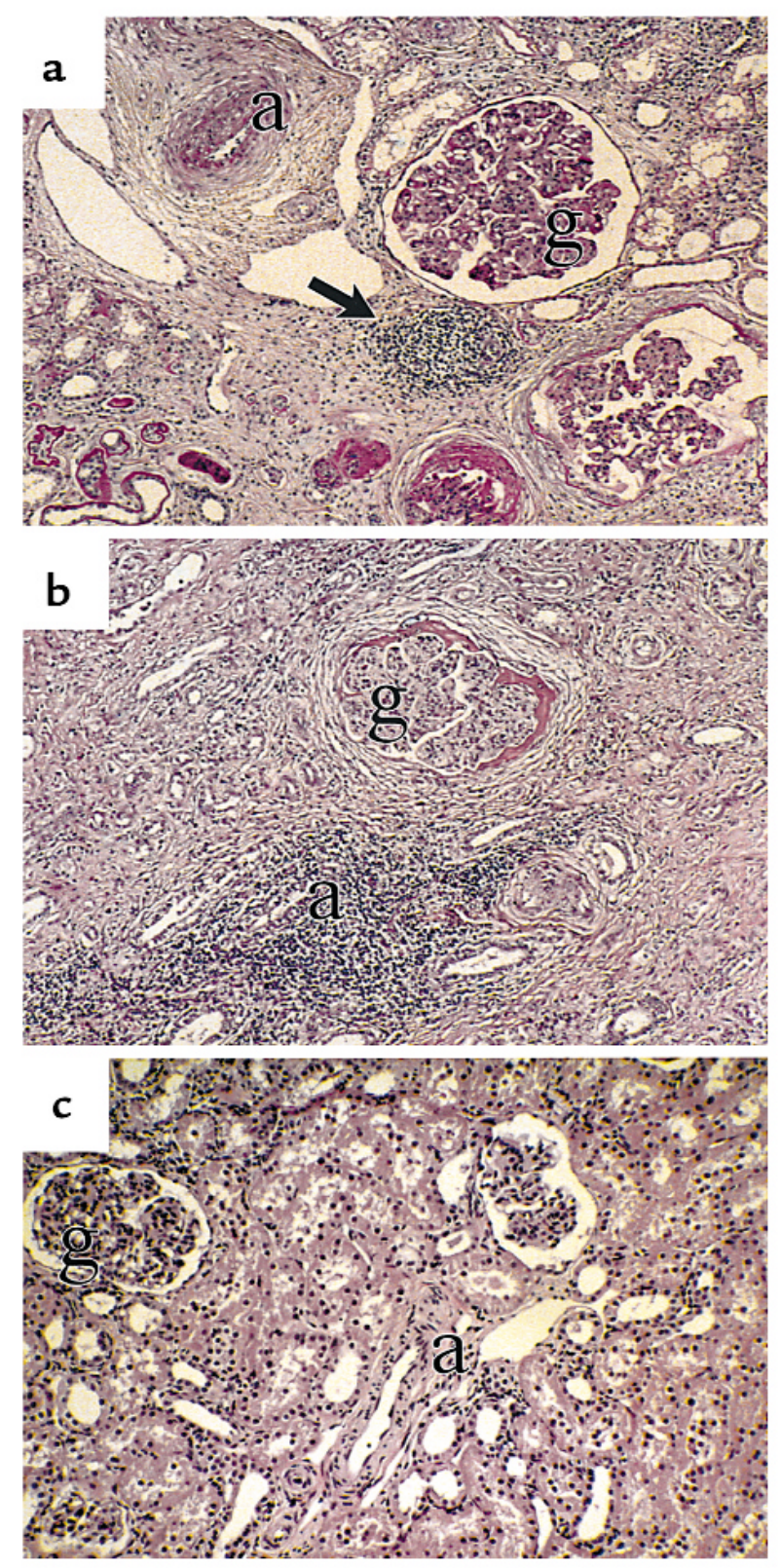

Figure 3

Histology of kidney biopsies from DRB- and DQA+B-treated animals, with hematoxylin and eosin staining. Arterioles (a) and glomeruli (g) are indicated. (a) Long-term graft-accepting pig no. 11585 at POD 322. There are typical signs of chronic rejection including chronic vasculopathy with intimal hyperplasia in small arteries, CAG, focal infiltration (arrow), and diffuse interstitial fibrosis. (b) Control animal no. 11625 at POD 82. Severe ACR with acute and severe endothelialitis in small vessels, diffuse mononuclear cell infiltration, and acute allograft glomerulopathy. (c) Tolerant animal no. 12307 at POD 100. No evidence of ACR, CAG, endothelialitis, or cellular infiltration. 


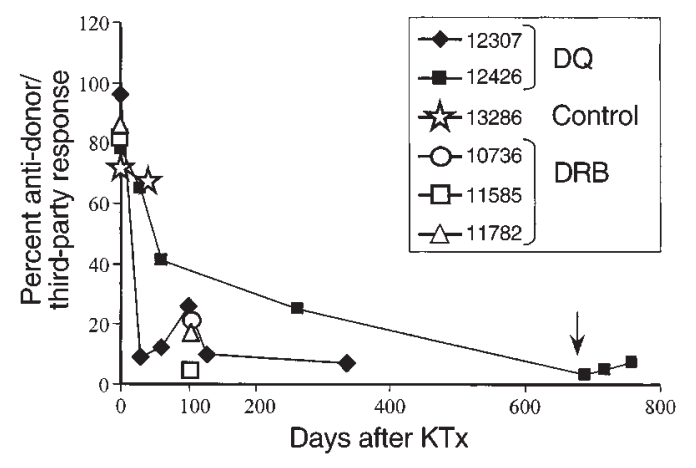

Figure 4

Peripheral T-cell reactivity of class II-treated animals. MLRs were performed as described in Methods. Anti-donor response is given as percent of the third-party response used as individual control in each experiment (anti-donor/third-party $\times 100)$. MLR assays were performed the day of the first $\mathrm{KTx}$ (day 0 ) and at indicated days thereafter for DQ and DR animals. The second KTx in animal no. 12426 (POD 658 after first transplant) is indicated by an arrow. T-cell proliferation of control animal no. 13286 was tested at PODs 0 and 35, four days prior to graft rejection.

dendritic cell precursors, which have also been implicated as modulators of the anti-graft response (16-18).

All of the DRB-engineered pigs, with the exception of animal no. 10736, eventually lost their grafts due to CAG and/or chronic rejection (Figures $2 \mathrm{a}$ and $3 \mathrm{a}$ ). Graft loss was not mediated through sensitization to donor-type antigens since these animals did not develop detectable levels of donor-specific antibodies. The fact that a DQ disparity between graft donor and host persisted in the DR-treated recipients could have accounted for the onset of delayed glomerulopathy. The animals receiving the DQA $+\mathrm{B} \mathrm{Tg}$ did not, however, develop such a pathology (Figures $2 \mathrm{~b}$ and $3 \mathrm{c}$ ). Alternatively, the differential effects of DR and DQ on tolerance induction might be related to a distinctive expression pattern, i.e., the surface assembly of the DR $\beta$ Tg product with the DR $\alpha$ chain relies on the endogenous production of the latter chain in the targeted transduced cells, whereas any $\mathrm{DQA}+\mathrm{B}$ transduced cell type should be able to assemble the DQ heterodimer regardless of its intrinsic ability to express endogenous class II molecules. A final possibility may invoke posttranscriptional mechanisms, which have been implicated in the mutually exclusive expression of DR or DQ in human cell lines (19). Interestingly, human progenitors of hematopoietic cells were shown to express DR and DP before DQ (20-22).

Early expression of allogeneic class II had no effect on the recipient's peripheral anti-donor T-cell response prior to KTx, as evaluated by MLR (Figure 4). In addition, transcription of the $\mathrm{Tg}$ was not detectable in BMCs or WBC from DQ-engineered animals long before KTx (Figure 1). This result implies that induction of sustained hyporesponsiveness is not mediated solely by the class II Tg products but rather by a combination of events, which may be sequential, involving the transient expression of allogeneic class II (as dimers or peptides) and the presence of graft-associated antigens. The observation that the donor-specific T-cell response diminished only after kidney allograft implantation (Figure 4) directly implicates graft antigens, rather than class II microchimerism alone, in shaping graft-specific unresponsiveness as has been observed in other models $(23,24)$. The fact that the concomitant presence of the class II Tg and the graft itself was not required for induction of specific unresponsiveness implies that early, transient $\mathrm{Tg}$ expression may generate regulatory mechanisms, which persist after the cessation of class II Tg transcription. Given that these regulatory mechanisms are likely to be class II-dependent, and that our previous studies demonstrated selective involvement of CD4 Th1 cells in kidney rejection (25) as well as increased transcription of the IL-10 gene in accepted grafts (26), we hypothesize that $\mathrm{CD}^{+} \mathrm{Th} 2$ regulatory cells are involved in the early phase of tolerance induction. Such immunoregulatory control of peripheral tolerance has been described in other models $(27,28)$ and may operate by altering the activation pathway of antigen-presenting cells (18), local inhibition of T-cell functions with cytokines such as IL-4 and IL-10 (29-34), and/or direct interaction with $\mathrm{T}$ effector cells (35).

Our results support the view that transduction of recipient BMCs with allogeneic class II vectors for both the $\alpha$ and $\beta$ polypeptide chains affects the regulatory T-cell compartment of the recipient immune system to generate local and specific unresponsiveness to subsequent class II-matched renal allografts. These data also suggest that such an immunomodulatory therapy has potential to downregulate $\mathrm{T}$-dependent responses to grafted tissues and autoimmune antigens as well.

\section{Acknowledgments}

We thank A. Foley, M. Murphy, A. Hansen, K. Allison, V. Ferrara, and I. Lubenec for expert technical assistance; I. McMorrow, J. Iacomini, J. Madsen, and S. Pillai for critical reading of the manuscript; and L.A. Bernardo for assistance in manuscript preparation. K.-C. Sonntag and G. Haller were supported in part by a grant from Deutsche Forschungsgemeinschaft (DFG); D.W. Emery was supported in part by a fellowship from the Medical Foundation Inc./Charles A. King Trust (Boston, Massachusetts, USA). This work was supported by NIH grants 2RO1 AI31046 and 5RO1 HL46532, and by the Yates Foundation. Novartis Pharmaceuticals is also acknowledged for generously providing CsA.

\footnotetext{
1. Vanrenterghem, Y.F. 1997. Impact of new immunosuppressive agents on late graft outcome. Kidney Int. Suppl. 63:S81-S83.

2. Shaw, L.M., Kaplan, B., and Kaufman, D. 1996. Toxic effects of immunosuppressive drugs: mechanisms and strategies for controlling them. Clin. Chem. 42:1316-1321.

3. Rosengard, B.R., et al. 1992. Induction of specific tolerance to class I disparate renal allografts in miniature swine with cyclosporine. Transplanta-
} 
tion. 54:490-497.

4. Nojima, M., et al. 1996. The significant effect of HLA-DRB1 matching on acute rejection in kidney transplants. Transpl. Int. 9(Suppl. 1):S11-S15.

5. Emery, D.W., et al. 1997. Expression of an allogeneic MHC DRB transgene, through retroviral transduction of bone marrow, induces specific reduction of alloreactivity. Transplantation. 64:1414-1423.

6. Shafer, G.E., et al. 1991. Expression of a swine class II gene in murine bone marrow hematopoietic cells by retroviral-mediated gene transfer. Proc. Natl. Acad. Sci. USA. 88:9760-9764.

7. Shimada, H., et al. 1999. MHC class II alpha/beta heterodimeric cell surface molecules expressed from a single proviral genome. Hum. Gene Ther 10:2397-2405.

8. Emery, D.W., Shafer, G.E., Karson, E.M., Sachs, D.H., and LeGuern, C. 1993. Retrovirus-mediated transfer and expression of an allogeneic major histocompatibility complex class II DRB cDNA in swine bone marrow cultures. Blood. 81:2460-2465.

9. Smith, C.V., et al. 1992. Successful induction of long-term specific tolerance to fully allogeneic renal allografts in miniature swine. Transplantation. 53:438-444.

10. Hammerberg, C., and Schurig, G.G. 1986. Characterization of monoclonal antibodies directed against swine leukocytes. Vet. Immunol. Immunopathol. 11:107-121.

11. Pescovitz, M.D., Lunney, J.K., and Sachs, D.H. 1984. Preparation and characterization of monoclonal antibodies reactive with porcine PBL. $J$. Immunol. 133:368-375.

12. Colvin, R.B. 1996. The renal allograft biopsy. Kidney Int. 50:1069-1082

13. Solez, K. 1994. International standardization of criteria for histologic diagnosis of chronic rejection in renal allografts. Clin. Transplant. 8:345-350.

14. Pescovitz, M.D., Lunney, J.K., and Sachs, D.H. 1985. Murine anti-swine $\mathrm{T} 4$ and $\mathrm{T} 8$ monoclonal antibodies: distribution and effects on proliferative and cytotoxic T cells. J. Immunol. 134:37-44.

15. LeGuern, C., et al. 1995. Retrovirus-mediated transfer of MHC class II cDNA into swine bone marrow cells. J. Mol. Med. 73:269-278.

16. Sykes, M. 1996. Chimerism and central tolerance. Curr. Opin. Immunol. 8:694-703.

17. Matzinger, P. 1994. Tolerance, danger, and the extended family. Annu. Rev. Immunol. 12:991-1045.

18. Field, E.H., Gao, Q., Chen, N.X., and Rouse, T.M. 1997. Balancing the immune system for tolerance: a case for regulatory CD4 cells. Transplantation. 64:1-7.

19. De Lerma, B., Sartoris, S., Tosi, G., Nicolis, M., and Accolla, R.S. 1994. Evidence for a specific post-transcriptional mechanism controlling the expression of HLA-DQ, but not-DR and -DP, molecules. J. Immunol. 153:4530-4538.
20. Robinson, J., Sieff, C., Delia, D., Edwards, P.A., and Greaves, M. 1981. Expression of cell-surface HLA-DR, HLA-ABC and glycophorin during erythroid differentiation. Nature. 289:68-71.

21. Falkenburg, J.H., et al. 1984. Polymorphic and monomorphic HLA-DR determinants on human hematopoietic progenitor cells. Blood. 63:1125-1132.

22. Katz, F.E., Davis, L., Myers, C.D., and Greaves, M.F. 1985. Selective expression of class-II MHC antigens during hemopoietic differentiation. Exp. Hematol. 13:1182-1187.

23. Hamano, K., Rawsthorne, M.A., Bushell, A.R., Morris, P.J., and Wood, K.J. 1996. Evidence that the continued presence of the organ graft and not peripheral donor microchimerism is essential for maintenance of tolerance to alloantigen in vivo in anti-CD4 treated recipients. Transplantation. 62:856-860.

24. Ramsdell, F., and Fowlkes, B.J. 1992. Maintenance of in vivo tolerance by persistence of antigen. Science. 257:1130-1134.

25. Giangrande, I., et al. 1997. Selective increase in CD4-positive graft-infiltrating mononuclear cells among the infiltrates in class I disparate kidney grafts undergoing rejection. Transplantation. 63:722-728.

26. Blancho, G., et al. 1995. Molecular identification of porcine interleukin10: regulation of expression in a kidney allograft model. Proc. Natl. Acad. Sci. USA. 92:2800-2804.

27. Qin, S., et al. 1993. "Infectious" transplantation tolerance. Science. 259:974-977.

28. Van de Keere, F., and Tonegawa, S. 1998. CD4(+) T cells prevent spontaneous experimental autoimmune encephalomyelitis in anti-myelin basic protein T cell receptor transgenic mice. J. Exp. Med. 188:1875-1882.

29. Buer, J., et al. 1998. Interleukin 10 secretion and impaired effector function of major histocompatibility complex class II-restricted T cells anergized in vivo. J. Exp. Med. 187:177-183.

30. Groux, H., et al. 1997. A CD4+ T-cell subset inhibits antigen-specific Tcell responses and prevents colitis. Nature. 389:737-742.

31. Powell, T.J.J., and Streilein, J.W. 1990. Neonatal tolerance induction by class II alloantigens activates IL-4-secreting, tolerogen-responsive T cells. J. Immunol. 144:854-859.

32. Maeda, H., Takata, M., Takahashi, S., Ogoshi, S., and Fujimoto, S. 1994. Adoptive transfer of a Th2-like cell line prolongs MHC class II antigen disparate skin allograft survival in the mouse. Int. Immunol. 6:855-862.

33. Onodera, K., et al. 1997. Type 2 helper T cell-type cytokines and the development of "infectious" tolerance in rat cardiac allograft recipients. $J$. Immunol. 158:1572-1581.

34. Scully, R., et al. 1997. A role for Th2 cytokines in the suppression of CD8+ T cell-mediated graft rejection. Eur. J. Immunol. 27:1663-1670.

35. Chai, J.G., et al. 1999. Anergic T cells act as suppressor cells in vitro and in vivo. Eur. J. Immunol. 29:686-692. 